\title{
垂直磁化膜におけるバックリング様式
}

\section{Magnetization buckling in perpendicular magnetic films with columnar structure}

\author{
石井良博 鈴木 伸吾 \\ 函館工業高等専門学校 \\ Y.Ishii and S.Suzuki
}

\begin{abstract}
The magnetization buckling mode is studied in a perpendicular magnetic film with columnar structure. The calculated nucleation field $H_{\mathrm{N}}$ of the buckling mode is compared with $H_{\mathrm{N}}$ of the curling and coherent rotation modes. It is found that the buckling occurs only in the restricted condition of the diameter and axial ratio of the crystallites constituting the film. In addition $H_{\mathrm{N}}$ of the buckling mode is very close to $H_{\mathrm{N}}$ of the coherent rotation mode. Therefore the buckling mode is not required to be taken in account in a perpendicular magnetic film with columnar structure.
\end{abstract}

\section{1. まえがき}

$\mathrm{CoCr}$ 垂直磁化膜の磁化の反転機構は, コヒ ーレントな回転では説明できないことが知られて いる ${ }^{1,2)}$. 柱状構造をした垂直磁化膜における力 ーリング様式について多くの研究がなされ ${ }^{3-6)}$, 近年の垂直磁気記録における記録過程などの 解析には，媒体の磁化機構をカーリング様式で あると仮定しているものが多い ${ }^{7,8)}$. しかし, 結晶 磁気異方性が大きな材料では, 磁化はカーリン グ様式で回転するのが困難である, また，たとえ カーリング様式で磁化が回転しても，その臨界 磁界 (nucleation field) は, コヒーレントな回転の 場合とあまり変わらない9．

先の報告で, 著者らは垂直磁化膜においてつ アンニング様式が起きることが理論的に可能なこ とを示した ${ }^{109}$. しかし $\mathrm{CoCr}$ 膜は柱状構造をして いることから,ファンニング様式よりもむしろ，膜
面と垂直な方向にスピンの方向が連続して変化 するバックリング様式の方が合理的であると考え られる. バックリング様式は，無限長円柱ではほ

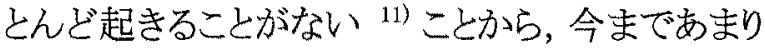
注目されていなかった。

本研究では, 柱状構造をした垂直磁化膜にお いて, バックリング様式によるスピンの挙動を考 察し, カーリング様式およびニヒーレントな回転と 比較することにより，バックリング様式の起きる 可能性について検討守る.

\section{2. 磁気エネルギー}

垂直磁化膜 Fig.1(a) のような, 四角柱の強 磁性の結晶粒が規則的に並んだものと考える. 隙間 $a \delta$ は非磁性層であり，結晶粒の間の交換 相互作用は，この隙間によって絶縁されていると 仮定する. 外部磁界 $H$ を $x z$ 平面の中で, $z$ 軸の 負の方向加 $\theta_{0}$ の角度で加える. このときの磁 性膜のエネルギ一密度 $\varepsilon$ は, 結晶磁気異方性 エネルギ一密度 $\varepsilon_{\mathrm{K}}$, 交換相互作用エネルギー 密度 $\varepsilon_{\mathrm{ex}}$, 外部磁界之磁化の間の静磁相互作用 エネルギー密度 $\varepsilon_{\mathrm{H}}$, および結晶粒の表面の磁 極による静磁工ネルギ一密度 $\varepsilon_{\mathrm{m}}$ の和として表さ れる.すなわち，

$$
\varepsilon=\varepsilon_{\mathrm{K}}+\varepsilon_{\mathrm{ex}}+\varepsilon_{\mathrm{H}}+\varepsilon_{\mathrm{m}} .
$$

結晶粒の中のスピンの方向は Fig.1(b)に示す

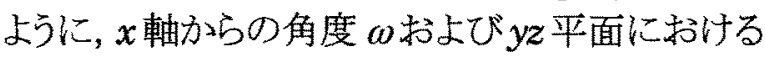
角度 $\phi$ によって表されるとする， $\omega$ は結晶粒の 中で一定で, $\phi$ は $z$ にの依存し, 次式で表され るとする. 


$$
\phi=\phi_{\mathrm{m}} \cos (m \pi z / t),
$$

ここに， $m$ は整数である.このように仮定すること により, 膜面における磁化の傾きは最大になり膜 面の磁極が小さくなって静磁エネルギーも低く なる.

結晶粒の結晶磁気異方性の磁化容易方向は $z$ 軸と一致し, 異方性定数を $K$ とする. そのときの $\varepsilon_{\mathrm{K}}$ は次式で表される.

$$
\begin{aligned}
\varepsilon_{\mathrm{K}} & =\frac{p}{t} \int_{0}^{t}-K \sin ^{2} \omega \cos \phi d z \\
& =p K\left[-1+\left(\phi_{\mathrm{m}}^{2} / 2\right)\right] \sin ^{2} \omega,
\end{aligned}
$$

ここに, $p$ 怗積率 $1 /(1+\delta)^{2}$ である．また， バックリングの開始の瞬間は, $\phi \ll 1$ であるので $\cos \phi=1-\left(\phi^{2} / 2\right)$ を用いた。

交換相互作用エネルギー密度 $\varepsilon_{\mathrm{ex}}$ は次式で与 えられる.

$$
\varepsilon_{\mathrm{ex}}=\frac{p}{t} \int_{0}^{t} A \sum_{i}\left(\nabla \alpha_{i}\right)^{2} d z,
$$

ここに, $A$ は交換相互作用定数で， $\alpha_{i}$ 柱磁化 $M_{\mathrm{S}}$ の方向余弦である. (4)式は, 次のように変換さ れる。

$$
\begin{aligned}
& \varepsilon_{\mathrm{ex}}=\frac{p}{t} \int_{0}^{t} A(m \pi / t)^{2} \phi_{\mathrm{m}}^{2} \sin ^{2} \omega \\
& \quad \times \sin ^{2}(m \pi z / t) d z \\
& =p\left(M_{\mathrm{S}}^{2} R_{0}^{2} / 4 \pi \mu_{0}\right)(m \pi / t)^{2}\left(\phi_{\mathrm{m}}^{2} / 2\right) \sin ^{2} \omega \\
& =p\left(M_{\mathrm{S}}{ }^{2} / \mu_{0}\right)\left[\pi m^{2} / 32 n^{2} S^{2}\right] \phi_{\mathrm{m}}^{2} \sin ^{2} \omega,
\end{aligned}
$$

ここに, $n$ は結晶粒の軸比 $t / a, \mu_{0}$ は真空の透磁 率である.また $R_{0}^{2}=4 \pi \mu_{0} A / M_{\mathrm{S}}^{2}$ および $S=a / 2 R_{0}$ の関係を用いた。
外部磁界 $H$ と磁化の間の静磁相互作用エネ ルギー密度 $\varepsilon_{\mathrm{H}}$ は次式で表される。

$$
\begin{gathered}
\varepsilon_{\mathrm{H}}=\frac{p}{t} \int_{0}^{t}-M_{S} H\left(\sin \theta_{0} \cos \omega\right. \\
\left.\quad-\cos \theta_{0} \sin \omega \cos \phi\right) d z \\
=p\left(M_{\mathrm{S}}^{2} / \mu_{0}\right) h\left[\sin \left(\omega-\theta_{0}\right)\right. \\
\left.-\left(\phi_{\mathrm{m}}^{2} / 4\right) \cos \theta_{0} \sin \omega\right]
\end{gathered}
$$

ここに, $h=M_{\mathrm{S}} H / \mu_{0}$ である.

結晶粒の表面の磁極による静磁エネルギー密 度 $\varepsilon_{\mathrm{m}}$ は, さらに $x, y, z$ 面のそれぞれの磁極によ るエネルギー密度 $\varepsilon_{\mathrm{m} x}, \varepsilon_{\mathrm{m} y}, \varepsilon_{\mathrm{m} z}$ の和として表わ される. $x$ 面の磁極 $\sigma_{x}=M_{\mathrm{S}} \cos \omega$ は, $z$ に依存し ないので, $\varepsilon_{\mathrm{m} x}$ は $x$ 軸方向の反磁界係数 $N_{x}$ を用 いて次のように表される.

$$
\varepsilon_{\mathrm{m} x}=p\left(M_{\mathrm{S}}^{2} / \mu_{0}\right)\left(N_{x} / 2\right) \cos ^{2} \omega .
$$

次に $\varepsilon_{\mathrm{m} y}$ を計算する. 線磁極 $\rho$ から距離 $r$ のと ころのポテンシャルは $\varphi=-\rho \ln (r) / 2 \pi \mu_{0}$ で与え られる.隙間 $a \delta$ 考慮して平均の線磁極を $\rho=\sigma_{y}(z) d z /(1+\delta)$ とすると, 1 個の結晶粒の $y$ 面 の磁極による静磁エネルギーは次式で表され る.

$$
\begin{aligned}
E_{\mathrm{msy}} & =\frac{a}{2 \pi \mu_{0}(1+\delta)} \int_{0}^{t} \int_{0}^{t} \sigma_{y}(z) \sigma_{y}\left(z^{\prime}\right) \\
& \times \ln \left(\sqrt{\left(z-z^{\prime}\right)^{2}+a^{2}} /\left|z-z^{\prime}\right|\right) d z d z^{\prime}
\end{aligned}
$$

$\sigma_{y}=M_{\mathrm{s}} \sin \omega \sin \phi$ を用いて, さらに, 他の結晶 粒との相互作用も含めると,

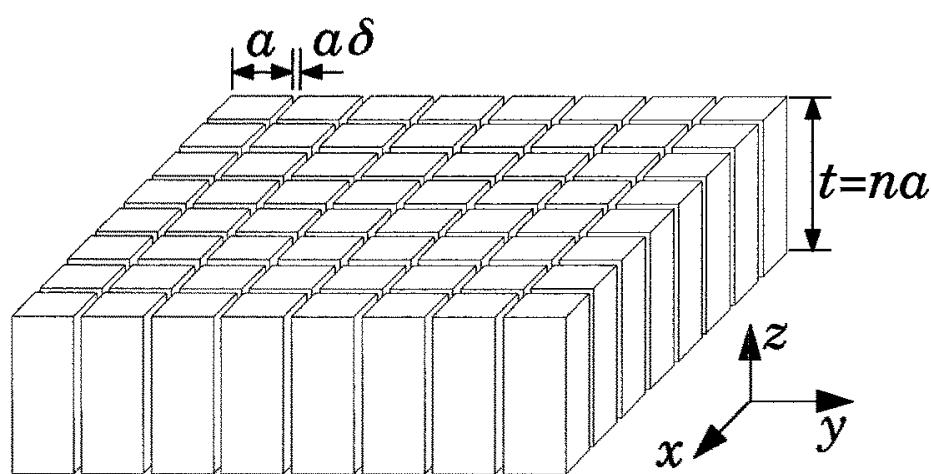

(a)

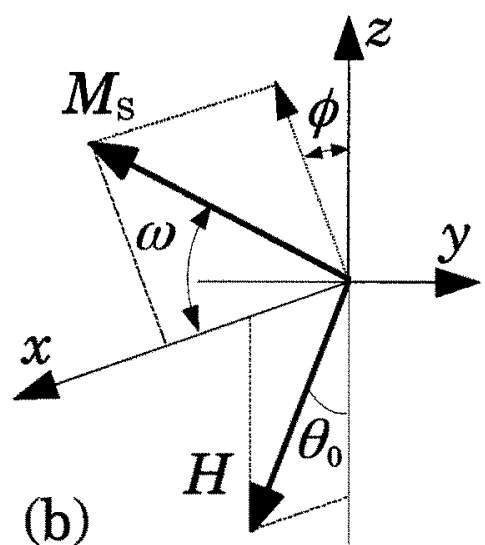

(b)

Fig.1 垂直磁化膜のモデルおよび磁界と磁化の方向. 


$$
\begin{aligned}
\varepsilon_{\mathrm{m} y} & =\left(E_{\mathrm{ms} y}+E_{\mathrm{mm} y}\right) /(a+a \delta)^{2} t \\
& =p\left(M_{\mathrm{S}}^{2} / \mu_{0}\right)(1 / 4 \pi n) \phi_{\mathrm{m}}^{2} \sin ^{2} \omega \\
& \times\left[\mathrm{G}(n, \delta, i=0) / 2+\sum_{i=1}^{\infty} \mathrm{G}(n, \delta, i)\right],
\end{aligned}
$$

ここに, $\mathrm{G}(n, \delta, i)$ は次式で定義される関数であ る.

$$
\begin{aligned}
& \mathrm{G}(n, \delta, i)=\frac{1}{1+\delta} \int_{0}^{n} \int_{0}^{n} \cos \frac{m \pi \xi}{n} \cos \frac{m \pi \xi^{\prime}}{n} \\
& \quad \times \ln \left(\left\{[i(1+\delta)-1]^{2}+\left(\zeta-\xi^{\prime}\right)^{2}\right\}\right. \\
& \quad \times\left\{[i(1+\delta)+1]^{2}+\left(\zeta-\zeta^{\prime}\right)^{2}\right\} \\
& \left.\quad \times\left\{[i(1+\delta)]^{2}+\left(\zeta-\xi^{\prime}\right)^{2}\right\}^{-2}\right) d \zeta d \xi^{\prime} .(10)
\end{aligned}
$$

$\varepsilon_{\mathrm{m} z}$ は $z$ 面および結晶粒内の磁極によるエネ ルギーで次式で表される.

$\varepsilon_{\mathrm{m} z}=\frac{p}{t} \int_{0}^{t} \frac{1}{2} H_{\mathrm{d}}(z) M_{z}(z) d z$,

ここで, $M_{z}(z)$ は $z$ における $M_{\mathrm{S}}$ の $z$ 軸方向成分, $H_{\mathrm{d}}(z)$ は結晶粒の面および結晶粒内の磁極によ る磁界で, それぞれ次式で表される。

$$
\begin{aligned}
& M_{z}(z)=M_{\mathrm{S}} \sin \omega \cos \phi \\
& =M_{\mathrm{S}} \sin \omega\left[1-\left(\phi_{\mathrm{m}}^{2} / 2\right) \cos \right. \\
& H_{\mathrm{d}}(z)=\frac{N_{z}}{\mu_{0}}\left[\sigma_{z}+\int_{z}^{t} \rho d z\right], \\
& \sigma_{z}=M_{z}(t), \\
& \rho=-\partial M_{z}(z) / \partial z,
\end{aligned}
$$$$
=M_{\mathrm{S}} \sin \omega\left[1-\left(\phi_{\mathrm{m}}^{2} / 2\right) \cos ^{2}(\pi z / t)\right] \text {, }
$$

ここで, $N_{z}$ は $z$ 軸に沿った反磁界係数である.し たがって, (11)式は次のようになる.

$$
\begin{aligned}
& \varepsilon_{\mathrm{m} z}=\frac{p}{t} \int_{0}^{t} \frac{N_{z} M_{z}(z)^{2}}{2 \mu_{0}} d z \\
& \quad=p\left(M_{\mathrm{S}}^{2} / \mu_{0}\right)\left(N_{z} / 2\right) \sin ^{2} \omega\left(1-\phi_{\mathrm{m}}^{2} / 2\right) .
\end{aligned}
$$

(13)式においいて, $\phi_{\mathrm{m}}{ }^{4}$ の項を無視している.

結局エネルギー密度は，(1)式より，(3),(5), (6),(7),(9),(13)式を用いて得られ，次のようにま とめられる.

$$
\begin{aligned}
& \varepsilon=\left(-K_{\mathrm{u}}+\beta \phi_{\mathrm{m}}^{2} / 2\right) \sin ^{2} \omega+M_{\mathrm{S}} H \\
& \times\left[\sin \left(\omega-\theta_{0}\right)-\left(\phi_{\mathrm{m}}^{2} / 4\right) \cos \theta_{0} \sin \omega\right],
\end{aligned}
$$
ここに,

$$
\begin{aligned}
K_{\mathrm{u}} & =p\left(M_{\mathrm{S}}^{2} / \mu_{0}\right)\left[\left(\mu_{0} K / M_{\mathrm{S}}^{2}\right)\right. \\
& \left.+\left(N_{x}-N_{z}\right) / 2\right] \\
\beta & =p \frac{M_{\mathrm{S}}^{2}}{\mu_{0}}\left\{\frac{\mu_{0} K}{M_{\mathrm{S}}^{2}}-\frac{N_{z}}{2}+\frac{\pi m^{2}}{16 n^{2}} S^{-2}\right. \\
& \left.+\frac{1}{2 \pi n}\left[\frac{\mathrm{G}(n, \delta, i=0)}{2}+\sum_{i=1}^{\infty} \mathrm{G}(n, \delta, i)\right]\right\} .
\end{aligned}
$$

\section{3. 磁化反転の臨界磁界}

最初, 全ての結晶粒のスピンは $z$ 軸と平行で あるとする.これに角度 $\theta_{0}$ で加えた外部磁界 $H$ が臨界磁界 $H_{\mathrm{N}}$ と等しくなったとき, スピンはバッ クリングにより回転すると考える.このとき， $\phi_{\mathrm{m}}=0$ において, 次の条件が同時に満足されなければ ならない ${ }^{12)}$.

$$
\begin{aligned}
& \partial \varepsilon / \partial \omega=0, \\
& \partial \varepsilon / \partial \phi_{\mathrm{m}}=0, \\
& \left|\begin{array}{cc}
\partial^{2} \varepsilon / \partial \omega^{2} & \partial^{2} \varepsilon / \partial \omega \partial \phi_{\mathrm{m}} \\
\partial^{2} \varepsilon / \partial \omega \partial \phi_{\mathrm{m}} & \partial^{2} \varepsilon / \partial \phi_{\mathrm{m}}^{2}
\end{array}\right|=0 \\
& \partial^{2} \varepsilon / \partial \omega^{2}>0 \\
& \partial^{2} \varepsilon / \partial \phi_{\mathrm{m}}^{2} \geq 0 .
\end{aligned}
$$

(14)式を(16)式に代入することにより臨界磁 界が得られる. $\phi_{\mathrm{m}}=0$ のとき， $(16 \mathrm{~b})$ 式および $\partial^{2} \varepsilon / \partial \omega \partial \phi_{\mathrm{m}}=0$ が成立する. 結局, (16a) 式と $\partial^{2} \varepsilon / \partial \phi_{\mathrm{m}}^{2}=0$ の連立方程式を解くことによって, $H_{\mathrm{N}}$ は次式のように得られる.

$$
\begin{aligned}
& h_{\mathrm{N}}=\mu_{0} H_{\mathrm{N}} / M_{\mathrm{S}}=2\left(\mu_{0} K_{\mathrm{u}}^{\prime} / M_{\mathrm{S}}^{2}\right) \\
& \quad \times\left[\sin ^{2} \theta_{0}+\left(K_{\mathrm{u}}^{\prime} / \beta\right)^{2} \cos ^{2} \theta_{0}\right]^{-1 / 2}, \\
& \quad(17 \mathrm{a}) \\
& K_{\mathrm{u}}^{\prime}=K_{\mathrm{u}}-\beta, \\
& \tan \theta_{0} \leq\left(K_{\mathrm{u}}^{\prime} / \beta\right)^{3 / 2} .
\end{aligned}
$$


ただし,バックリングによる回転は外部磁界を加 える角度 $\theta_{0} か ゙(17 \mathrm{c})$ 式の範囲で起こり，それ以上 の $\theta_{0}$ ではコヒーレントな回転になる.

$\theta_{0}=0$ の場合の $h_{\mathrm{N}}$ は, (17a)式より

$$
h_{\mathrm{N}}=2 \beta \text {. }
$$

で表される.また, コヒーレントな回転およびカー リング様式の $h_{\mathrm{N}}$ は, それぞれ $(19 \mathrm{a}),(19 \mathrm{~b})$ 式で 与えられる.

$$
\begin{aligned}
& h_{\mathrm{N}}=\left(2 \mu_{0} K / M_{\mathrm{S}}^{2}\right)-N_{z}+N_{x}, \\
& h_{\mathrm{N}}=\left(2 \mu_{0} K / M_{\mathrm{S}}^{2}\right)-N_{z}+1.08 S^{-2} .
\end{aligned}
$$

(18),(19a)，(19b)式を用いて， $\mu_{0} K / M_{\mathrm{S}}^{2}=0.5$ のときの $h_{\mathrm{N}}$ と $S$ の関係を Fig.2 に示す. (18),(19a)，(19b)式には $K$ が同じ形で含まれて

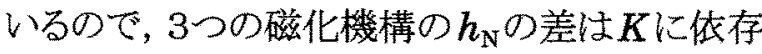
せず，またこれらの磁化機構の起きるSの範囲 も $K$ によって変わらない. $\delta=0.1$ の場合, $n=5$

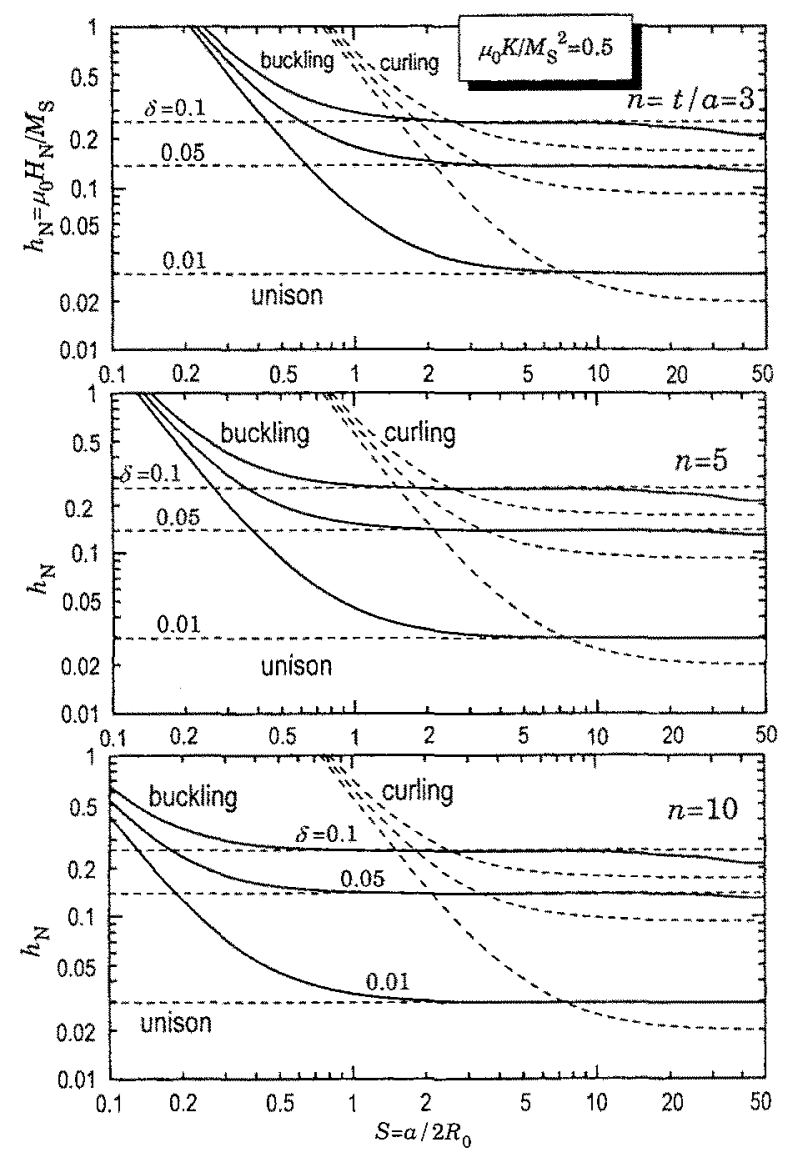

Fig.2 磁界が膜面と垂直な場合におけるバックリ ング, カーリング, コヒーレントな回転(unison) $\infty h_{\mathrm{N}} \cdot \mu_{0} K / M_{\mathrm{S}}^{2}=0.5$
では $S$ が約 1.5 から 2.5 の範囲で, $n=10$ では $S$ が約 0.8 から 2.5 の範囲でバックリングが起きる.

Fig.2 では, その他の条件ではバックリングは起 きていない，また，上に述べた範讲でバックリン グが起きても,バックリング様式の $h_{\mathrm{N}}$ の大きさは， コヒーレントな回転の $h_{\mathrm{N}}$ とほとんど変わらない．

$S$ の大きい範囲で, バックリングの $h_{\mathrm{N}}$ が減少し ているのは， $m$ の増大(バックリングの周期の短 縮)による効果である. Fig.3に， $h_{\mathrm{N}}$ とSの関係 の $m$ による変化を示す. $m$ の増大により, $S$ の大きな範囲では $\varepsilon_{\mathrm{m} x}$ の減少により， $h_{\mathrm{N}}$ がわ ずかに低下するが，この $\boldsymbol{S}$ の範囲ではカーリン グ様式の $h_{\mathrm{N}}$ の方がさらに小さいので, バックリン グは起きない.一方， $S$ の小さな範囲では， $m$ が大きくなると $\varepsilon_{\mathrm{ex}}$ が大きくなって $h_{\mathrm{N}}$ は急增する。

(16)式を用いて $h_{\mathrm{N}}$ の角度依存性を計算し, Fig.4に示守. Fig.4から明らかなように, バックリ ングの起きる $\theta_{0}$ の範囲は非常に小さく, $\theta_{0}$ の増

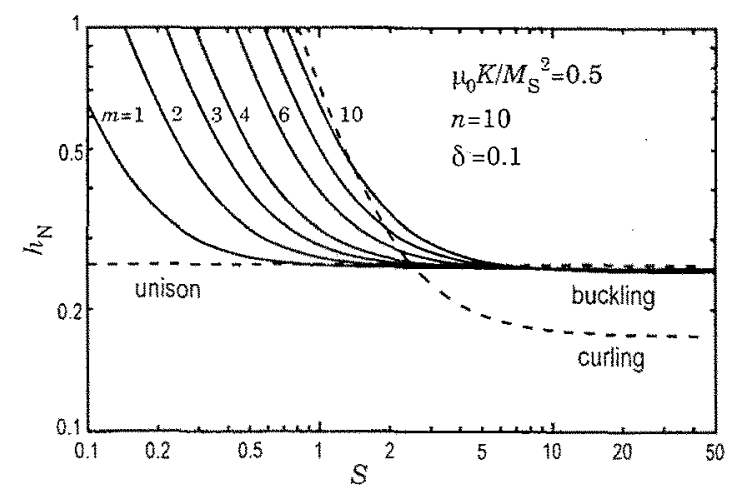

Fig.3 $m$ の変化による $h_{\mathrm{N}} よ S$ 関倸の変化.

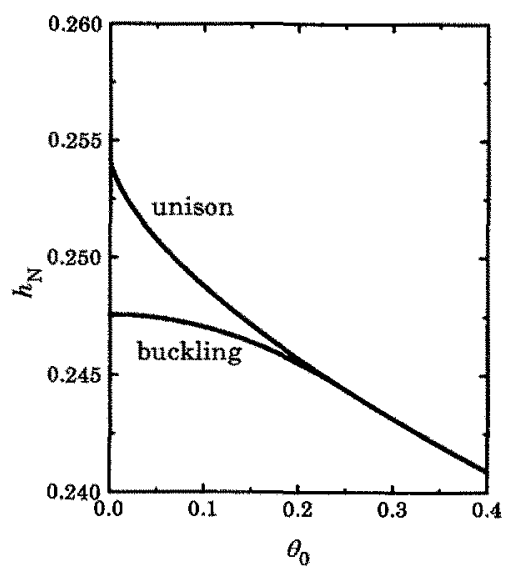

Fig. $4 h_{\mathrm{N}}$ の角度依存性. 
加とともに， $h_{\mathrm{N}}$ はコヒーーレントな回転の $h_{\mathrm{N}}$ に接 近し，(17c）式から得られる $\theta_{0}$ でコヒーレントな 回転に代わってしまう。

\section{4. まとめ}

柱状構造をした垂直磁化膜において, バックリ ング様式による磁化の回転について考察した結 果，以下のことがわかった。

（1）S の減少にともなって, 磁化の回転様式 は, カーリング, バックリング, コヒーレントな回 転の順で代わる.

（2）しかし, バックリングの起きる $\boldsymbol{S}$ の範囲は 狭く, $n, \delta$ が小さいときは, バックリングの起き るS の範囲はない.

（3）バックリングの周期が短くなることによって $H_{\mathrm{N}}$ が低下寸るのは $S$ が大きな場合である.し かし, この場合, カーリングの $H_{\mathrm{N}}$ はさらに小さ く,バックリングは起きない。

（4）バックリングが起きたとしても， $H_{N}$ はコヒ 一レントな回転の $H_{\mathrm{N}}$ とほとんど変わらない。

（5）外部磁界が膜面と垂直な場合にバックリ ングが起きる $S$ の範囲においても, バックリン グの起きる $\theta_{0}$ の範囲は非常に小さい.

以上のことから，柱状構造をした垂直磁気記 録媒体においてバックリング様式考える必要 はほとんどない。

垂直磁気記録媒体の記録密度を高めるため に, 結晶粒径を小さくするのは必然である.この ような, 小さな $S$ の結晶粒ではカーリングが起き ることは不可能であり, 本研究の結果, バックリン グ様式も起き得ないことが明らかになった.した がって，すでに知られている非コヒーレントな磁 化機構柱柱状の結晶粒の中で起きることはない と結論せざるを得ない。

以上の結論と, $\mathrm{CoCr}$ 膜の磁化過程をコヒーレ ントな回転では説明できない 1,2)ことを考穴合わ せると，個々の結晶粒の中では磁化がコヒーレ ントに回転し, 隣り合った結晶粒の磁化の方向 が異なるような新しい回転様式のモデルを発案 する必要があると考えられる。
付記 本論文の研究は一部, ホクサイテック財 団 研究開発支援事業の補助 (平成8年度 共036)によった.

\section{参考文献}

1) 中村慶久, 大谷毅, 岩崎俊一: 日本応用磁気学 会誌, 10, 109(1986).

2) 廣野滋, 古谷彰教, 寺田章:電子情報通信学 会技術研究報告, MR87-8(1987).

3) H.Danan and W.Andra: J.Magn.Magn. Mat.35,299(1983).

4) G.T.A.Huysmans, J.C.Lodder, and J. Wakui: J.Appl.Phys. 64,2016(1988).

5) Y.Ishii and M.Sato: J.Magn.Magn.Mat. 82 (1989).

6) K.Ouchi and S.Iwasaki: IEEE Trans. Magn.MAG-23, 180(1987).

7) Y.Nakamura and S.Iwasaki: IEEE Trans. Magn.MAG-23, 153(1987).

8) 竹尾昭彦, 田河育也, 中村慶久:日本店用磁 気学会誌, 19, 97(1995).

9) Y.ishii: J.Appl.Phys. 70(1991)3765.

10) 石井良博ほか: 日本応用磁気学会誌, 19. 712(1995).

11) E.H.Frei, S.Shtrikman, and D.Treves: Phys.Rev.106,446(1957).

12) Y.ishii and M.Sato: J.Appl.Phys. 57 (1985)465. 